Crewe, T. L., P. D. Taylor, and D. Lepage. 2016. Temporal aggregation of migration counts can improve accuracy and precision of trends. Avian Conservation and Ecology 11(2):8. http://dx.doi.org/10.5751/ACE-00907-110208

Copyright (C) 2016 by the author(s). Published here under license by the Resilience Alliance.

Research Paper

\title{
Temporal aggregation of migration counts can improve accuracy and precision of trends
}

\author{
Tara L. Crewe ${ }^{1,2}$, Philip D. Taylor ${ }^{2,3}$ and Denis Lepage ${ }^{2}$ \\ ${ }^{1}$ Western University, Canada, ${ }^{2}$ Bird Studies Canada, ${ }^{3}$ Acadia University, Canada
}

\begin{abstract}
Temporal replicate counts are often aggregated to improve model fit by reducing zero-inflation and count variability, and in the case of migration counts collected hourly throughout a migration, allows one to ignore nonindependence. However, aggregation can represent a loss of potentially useful information on the hourly or seasonal distribution of counts, which might impact our ability to estimate reliable trends. We simulated 20-year hourly raptor migration count datasets with known rate of change to test the effect of aggregating hourly counts to daily or annual totals on our ability to recover known trend. We simulated data for three types of species, to test whether results varied with species abundance or migration strategy: a commonly detected species, e.g., Northern Harrier, Circus cyaneus; a rarely detected species, e.g., Peregrine Falcon, Falco peregrinus; and a species typically counted in large aggregations with overdispersed counts, e.g., Broad-winged Hawk, Buteo platypterus. We compared accuracy and precision of estimated trends across species and count types (hourly/daily/annual) using hierarchical models that assumed a Poisson, negative binomial (NB) or zero-inflated negative binomial (ZINB) count distribution. We found little benefit of modeling zero-inflation or of modeling the hourly distribution of migration counts. For the rare species, trends analyzed using daily totals and an NB or ZINB data distribution resulted in a higher probability of detecting an accurate and precise trend. In contrast, trends of the common and overdispersed species benefited from aggregation to annual totals, and for the overdispersed species in particular, trends estimating using annual totals were more precise, and resulted in lower probabilities of estimating a trend (1) in the wrong direction, or (2) with credible intervals that excluded the true trend, as compared with hourly and daily counts.
\end{abstract}

\section{Le regroupement à différentes échelles temporelles de dénombrements d'oiseaux en migration peut améliorer l'exactitude et la précision des tendances}

RÉSUMÉ. Le regroupement des dénombrements répétés dans le temps est une technique souvent utilisée pour réduire la surreprésentation de zéros et la variabilité des dénombrements, et ultimement améliorer l'ajustement des modèles. Dans les cas de dénombrements d'oiseaux en migration faits à chaque heure durant la période de migration, ce regroupement des données permet aussi d'ignorer la non-indépendance. Toutefois, ce regroupement peut mener à une perte d'informations potentiellement utiles sur la distribution horaire ou saisonnière des dénombrements, pouvant en retour affecter notre capacité à obtenir des estimations fiables des tendances. Nous avons simulé des données de dénombrements de rapaces en migration réalisés à chaque heure pendant 20 ans et dont le taux de changement était connu afin de tester l'effet du regroupement des dénombrements faits à l'heure en totaux quotidiens ou annuels sur notre capacité de détecter la tendance connue. Nous avons simulé des données pour trois types d'espèces dans le but de voir si les résultats variaient avec l'abondance de l'espèce ou sa stratégie de migration : une espèce communément détectée, p. ex. le Busard St-Martin, Circus cyaneus; une espèce rarement détectée, p. ex. le Faucon pèlerin, Falco peregrinus; et une espèce typiquement dénombrée en gros groupes avec des dénombrements surdispersés, p. ex. la Petite Buse, Buteo platypterus. Nous avons comparé l'exactitude et la précision des tendances estimées pour les trois espèces et les types de dénombrements (à l'heure/quotidiens/annuels) au moyen de modèles hiérarchiques qui assumaient une distribution des données selon les lois de Poisson, binomiale négative (BN) ou binomiale négative avec une surreprésentation de zéros (BNSZ). Nous avons constaté qu'il y avait peu d'avantages à modéliser la surreprésentation de zéros ou à modéliser la distribution horaire des dénombrements faits en migration. Pour les espèces rares, les tendances analysées à l'aide des totaux quotidiens et une distribution des données BN ou BNSZ ont montré une plus grande probabilité de détecter une tendance exacte et précise. À l'opposé, les tendances des espèces communes ou dont les dénombrements étaient surdispersés gagnaient à être regroupées en totaux annuels et, particulièrement pour les espèces surdispersées, les tendances estimées au moyen des totaux annuels étaient plus précises et avaient des probabilités plus faibles d'estimer une tendance (1) dans la mauvaise direction ou (2) avec des intervalles de crédibilité qui excluaient la vraie tendance, comparativement aux dénombrements faits à l'heure ou au quotidien.

Key Words: accuracy; Bayesian; bias; count aggregation; hierarchical models; migration monitoring; population trend; precision; zeroinflation 


\section{INTRODUCTION}

Population monitoring programs often use temporal or spatial replicate counts of animals to estimate long-term population trends (Link and Sauer 2002, Farmer et al. 2007, Kéry et al. 2009, Fedy and Aldridge 2011). During analysis, counts are often aggregated, for example, by taking the maximum abundance across repeated visits of an assumed closed population (Fedy and Aldridge 2011), or total abundance across assumed independent stops along a survey route (Link et al. 2008). Similarly, hourly or daily counts of the number of individuals migrating past or stopped at a specific geographic location (migration counts), which are assumed to detect a new cohort of migrants during each sampling occasion (Dunn 2005), are also often aggregated to daily or annual totals to estimate long-term trends in the count population (Farmer et al. 2007, Knudsen et al. 2007). Aggregating counts to a higher level can reduce zero-inflation and count variability, and allows one to ignore or "assume away" temporal autocorrelation (nonindependence) of hourly and/or daily migration counts. This has the potential to improve model fit and increase precision of trends, particularly for species with highly variable counts (Miller et al. 2002).

However, the temporal aggregation of counts can result in the loss of potentially useful information. Analytical methods to estimate population trends from count data are in a constant state of development (Hochachka and Fiedler 2008, Kéry and Royle 2010, Dail and Madsen 2011, Ross et al. 2012, Dennis et al. 2016), and methods are now available that can garner information from nonaggregated count data that was lost using previous analysis techniques. This includes the estimation of detection probability from repeated counts (Kéry et al. 2009, Kéry and Royle 2010) and home range centers from spatial mark-recapture data (Royle et al. 2013). In terms of typical hourly raptor migration counts, the realized count is a product of the size of the migratory population $(N)$ and the probability that migrants will be detected $(p)$ at the count site (Counts $=N \times p$; Nichols et al. 2009). In other words, detection and abundance are confounded and variation in detection cannot be estimated without the collection of additional data (e.g., a double-surveyor approach can be used to estimate one component of detection probability, i.e., observer detection given presence during the count period; Berthiaume et al. 2009). Thus, the primary information lost by aggregating hourly raptor migration counts to daily or annual totals is information about the hourly and seasonal distribution of counts. Modeling the seasonal distribution of counts can account for missing observations, which may improve the precision of long-term trends (Dennis et al. 2013).

Further, in the past decade, regression techniques that accommodate overdispersed, zero-inflated, and temporally autocorrelated counts have become more common and accessible (e.g., Ross et al. 2012). A negative binomial distribution of counts is often assumed when variance is larger than the mean, and a zero-inflation parameter can model excess zero-observation counts that arise from true absence or nondetection given presence (Zipkin et al. 2010, Ross et al. 2012). Importantly, the ability to model the hierarchical structure of errors among hourly, daily, and annual counts, and to acknowledge and model temporal autocorrelation of counts, can result in more realistic estimates of precision that better reflect the true variability in the data (Ross et al. 2012). The effect of temporal aggregation of hourly raptor migration counts on the precision and accuracy of estimated trends, and whether aggregation is necessary given the more recent development of analytical tools that accommodate overdispersion, zero-inflation, and random errors, have not been validated using data with known underlying trend.

In this paper, we used simulated hourly raptor migration counts with known underlying rate of change, consistent effort, and constant detection probability over time, to test the effect of temporal aggregation of counts on accuracy and precision of estimated trends. We compared the recovery of known trend among raw hourly counts and daily or annual totals corrected for sampling effort. To test whether the effect of temporal aggregation of counts varied with species abundance or migration strategy, we simulated data to represent three types of count distributions, following the methodology of Crewe et al. (2016a): a commonly detected species (hereafter "common"), e.g., Northern Harrier, Circus cyaneus (Crewe et al. 2013); a rarely detected species with a high proportion of zero-observation counts (hereafter "rare"), e.g. Peregrine Falcon, Falco peregrinus (Crewe et al. 2013); and a common but super-flocking species with highly overdispersed counts (hereafter "over-dispersed"), e.g., Broad-winged Hawk, Buteo platypterus (Crewe et al. 2013). Further, we compared the recovery of simulated trend between a Poisson data model and a negative binomial data model with and without a zero-inflation parameter, to test whether modeling overdispersion and excess zero-observation counts improved model fit.

Currently, rare species are often excluded from trend analyses using migration counts (Bildstein et al. 2008, Crewe et al. 2008), and trend analyses for raptor migration are often restricted to sites that submit hourly counts (e.g., the Raptor Population Index, http://rpi-project.org/index.php). A large number of species and sites are thus excluded from trend updates. Results from this paper will help inform whether, given the tools currently available to data analysts, aggregation of migration counts is necessary or recommended in the estimation of population trends, and thus, whether the current restriction of analyses based on species abundance or submission of hourly count data is warranted.

\section{METHODS}

\section{Real migration count data}

We acquired hourly migration count data online through Nature Counts (http://naturecounts.ca/) for three raptor species detected at Hawk Mountain Sanctuary, Pennsylvania (1991-2010), which represented the following: (1) a commonly detected migrant with low variation in counts among hours, days, and years (Northern Harrier); (2) a rarely detected migrant with low counts, but intermediate levels of variation in counts among hours and days (Peregrine Falcon); and (3) a commonly detected, super-flocking migrant with highly overdispersed hourly and daily counts (i.e., counts varied widely in magnitude among hours and days; Broadwinged Hawk). Migration counts were collected as the total number of individuals of each species detected flying overhead on an hourly basis during daylight hours (Barber et al. 2001). We included only the inner 95 th percentile of observation days across years for each species, to exclude outlying observations and excess zero-observation counts at the tail-ends of the migration. We also included only the inner 99th percentile of observation hours across days and years for each species, to exclude excess zeroobservations and hours of the day that were not typically sampled. We then summarized counts to calculate the mean, median and 
coefficient of variation (CV) of annual, daily, and hourly counts, and of the proportion of 0 -observation hours and days (Table A1.1).

\section{Simulated migration count data}

We simulated 100 20-year migration count datasets for all three species in $\mathrm{R}$ ( $\mathrm{R}$ Core Team 2014) using the simulation model described in Crewe et al. (2016a), and assuming a decline in the count population of $3.6 \%$ year $^{-1}$. The simulation model assumed a normal density for the daily and hourly distribution of counts, which allowed peak availability of migrants to occur midseason or midday, with added random and stochastic error (Crewe et al. 2016a). The daily count distribution was further modified by including a binomial probability that available birds were recruited to, or arrived at, the count site each day. Below a specified threshold, no birds arrived at the site on a given day, thus introducing zero-observation days, and resulting in a seasonal distribution of counts that more closely approximated a gamma than a normal distribution (see Crewe et al. 2016 $a$ for details and $\mathrm{R}$ code). Simulation parameter values (Table A2.1) were chosen such that simulated data approximated the distribution of real hourly and daily migration count data (Tables A2.1, A3.1, Figs. A3.1-A3.6).

Because datasets were simulated to have complete hourly, daily, and annual coverage at a site, we dropped observations from each dataset to mimic incomplete sampling coverage, which might occur, for example, at sites dependent on volunteers for data collection. To do so, we included counts collected on day $j$ and year $i\left(n_{i j}\right)$ with binomial probability $0.8\left(n_{i j}=\operatorname{binom}(1,0.8)\right)$, which resulted in the random exclusion of approximately $20 \%$ of observation days from each simulated dataset. For the remaining observation days, we dropped zero to six hours from the beginning or end of each day according to a Poisson distribution (nHoursDropped $_{i j}=\operatorname{Pois}\left(\lambda_{\mathrm{ij}}=1\right)$ ), which allowed a higher proportion of days having no hours dropped, and a decreasing proportion of days having one to six hours dropped from a given day. Hours were dropped from the beginning of the day with binomial probability 0.5 , which allowed an approximately equal distribution of days with hours being dropped from the beginning or end of the day, i.e., we simulated random, not systematic, variation in sampling effort over time. We did not drop hours midday, because it is more likely that surveys would either start late or end early on a given day depending on observer availability. We examined correspondence between real and simulated count distributions using quantile-quantile (qq) plots (qqplot function, $\mathrm{R}$ version 3.0.3; $\mathrm{R}$ Core Team 2014; Table A3.1) and plots of the daily and hourly distribution of counts (Figs. A3.1-A3.6). A Pearson correlation of qq-scores near 1 (an approximately 1:1 relationship) suggests a similar distribution of counts, even if counts in one dataset tend to be larger than in the other.

For each of the simulated datasets, we aggregated hourly counts into daily and annual totals by summing all counts across days and years, respectively. The number of hours sampled each day and year was also calculated and used as an offset variable to account for daily or annual variation in sampling effort in the regression analyses.

\section{Statistical analyses}

We analyzed all simulated datasets in a Bayesian framework using Integrated Nested Laplace Approximation (R-INLA; Rue et al.
2009) in $\mathrm{R}$ (version 3.0.3; R Core Team 2014). For a given count type (hourly, daily, or annual totals), we compared models that assumed (1) a Poisson data distribution where

$$
y \sim \operatorname{Poisson}(\mu)
$$

; (2) a negative binomial (NB) data distribution where

$$
y \sim N \operatorname{egBinom}(\mu, \varphi)
$$

; or (3) a zero-inflated NB (ZINB) data distribution (hourly and daily data only), where

$$
y \sim\left\{\begin{array}{lr}
0, & \text { with probability } p \\
\operatorname{NegBinom}(\mu, \varphi) & \text { with probability }(1-p)
\end{array}\right.
$$

An NB distribution is often assumed for overdispersed counts with variance greater than the mean, but will approximate a Poisson distribution when variance approaches the mean (Bolker 2008). A ZINB distribution was not considered for annual counts, because aggregating to annual totals would negate the need for a zero-inflated model. We fit all data models using log-linear regression, with a continuous year effect to estimate the overall log-linear trend in annual, daily, or hourly migration counts (Ross et al. 2012), and first and second order polynomial effects for day and hour to model the seasonal and hourly distribution of counts, respectively, where appropriate. Thus, for counts collected on year $i$, day $j$, and hour $k$, the linear regression models for annual, daily and hourly counts were:

$$
\begin{aligned}
& \text { Annual: } \log \left(\lambda_{i}\right)=\beta_{1} \times \text { year }_{i}+\gamma_{i} \\
& \text { Daily: } \log \left(\lambda_{i j}\right)= \beta_{1} \times \text { year }_{i j}+\beta_{2} \times d a y_{i j}+\beta_{3} \\
& \times d a y_{i j}^{2}+\gamma_{i}+\eta_{i j} \\
& \text { Hourly: } \log \left(\lambda_{i j k}\right) \\
&= \beta_{1} \times \text { year }_{i j k}+\beta_{2} \times d a y_{i j k}+\beta_{3} \\
& \times \text { day }_{i j k}^{2}+\beta_{4} \times \text { hour }_{i j k}+\beta_{5} \\
& \times \text { hour }_{i j k}^{2}+\gamma_{i}+\eta_{i j}+\delta_{k}
\end{aligned}
$$

where $\gamma_{i}$ is a hierarchical term to account for random variation in counts among years

$$
\left(\gamma_{i} \sim \operatorname{Normal}\left(0, \sigma_{\gamma}^{2}\right)\right)
$$

, and $\eta_{i j}$ and $\delta_{k}$ are first order autoregressive (AR1) hierarchical terms to account for temporal autocorrelation (Rue et al. 2009, Ross et al. 2012) among days within years and among hours, respectively. We did not include an AR 1 structure on the random year effect because estimated correlation (Rho) of the AR 1 effect for year was $1 \%$ or less across all simulated datasets for each species. To account for the simulated random variability in daily sampling effort, we included number of hours sampled each day or year as an offset variable in the daily and annual regressions, respectively. We back-transformed the year coefficient estimate into a rate of change on the response scale $\left(\% \mathrm{year}^{-1}\right)$ using $100 \times(\exp [$ year coefficient]-1). 
Table 1. Parameter estimates from linear models (Gaussian distribution) that examined the influence of count type (hourly, daily, or annual), model structure (negative binomial [NB], zero-inflated NB [ZINB], or Poisson [POIS]), and their interaction on bias (estimated - simulated trend) or half-width of the credible interval ( $0.5 \times$ [upper credible limit - lower credible limit]) of trends estimated for datasets simulated to represent a commonly detected species (e.g., Northern Harrier, Circus cyaneus, NOHA), a rarely detected species with zero-inflated counts (e.g., Peregrine Falcon, Falco peregrinus, PEFA), or a super-flocking species with highly overdispersed counts (e. g., Broad-winged Hawk, Buteo platypterus, BWHA).

\begin{tabular}{|c|c|c|c|c|c|c|c|c|c|}
\hline \multirow[b]{2}{*}{ Species } & \multirow[b]{2}{*}{ Parameter } & \multicolumn{4}{|c|}{ Bias } & \multicolumn{4}{|c|}{ Precision } \\
\hline & & Estimate & Std. Error & $\mathrm{t}$ value & $\operatorname{Pr}(>|t|)$ & Estimate & Std. Error & $\mathrm{t}$ value & $\operatorname{Pr}(>|t|)$ \\
\hline \multirow[t]{8}{*}{ NOHA } & Intercept (Hourly, NB) & -0.40 & 0.09 & -4.66 & $<0.01$ & 1.57 & 0.03 & 52.16 & $<0.01$ \\
\hline & Daily & 0.29 & 0.12 & 2.42 & 0.02 & -0.13 & 0.04 & -3.04 & $<0.01$ \\
\hline & Annual & 0.32 & 0.12 & 2.67 & 0.01 & 1.38 & 0.04 & 32.39 & $<0.01$ \\
\hline & ZINB & 0.01 & 0.12 & 0.05 & 0.96 & -0.01 & 0.04 & -0.31 & 0.76 \\
\hline & POIS & 0.15 & 0.12 & 1.24 & 0.21 & 0.03 & 0.04 & 0.73 & 0.47 \\
\hline & Daily:ZINB & 0.14 & 0.17 & 0.83 & 0.41 & 0.00 & 0.06 & 0.08 & 0.94 \\
\hline & Daily:POIS & -0.28 & 0.17 & -1.63 & 0.10 & 0.13 & 0.06 & 2.21 & 0.03 \\
\hline & Annual:POIS & -0.03 & 0.17 & -0.16 & 0.87 & -1.38 & 0.06 & -23.05 & $<0.01$ \\
\hline \multirow[t]{8}{*}{ PEFA } & Intercept (Hourly, NB) & -0.06 & 0.14 & -0.43 & 0.67 & 2.48 & 0.03 & 88.01 & $<0.01$ \\
\hline & Daily & 0.12 & 0.20 & 0.57 & 0.57 & 0.31 & 0.04 & 7.79 & $<0.01$ \\
\hline & Annual & 0.04 & 0.20 & 0.22 & 0.83 & 1.31 & 0.04 & 32.84 & $<0.01$ \\
\hline & ZINB & 0.25 & 0.20 & 1.25 & 0.21 & -0.23 & 0.04 & -5.81 & $<0.01$ \\
\hline & POIS & -0.09 & 0.21 & -0.41 & 0.68 & 0.28 & 0.04 & 6.84 & $<0.01$ \\
\hline & Daily:ZINB & -0.23 & 0.29 & -0.78 & 0.43 & 0.14 & 0.06 & 2.45 & 0.01 \\
\hline & Daily:POIS & -0.03 & 0.29 & -0.11 & 0.91 & -0.32 & 0.06 & -5.64 & $<0.01$ \\
\hline & Annual:POIS & 0.35 & 0.29 & 1.22 & 0.22 & -2.02 & 0.06 & -35.56 & $<0.01$ \\
\hline \multirow[t]{8}{*}{ BWHA } & Intercept (Hourly, NB) & -0.47 & 0.34 & -1.38 & 0.17 & 6.66 & 0.09 & 73.00 & $<0.01$ \\
\hline & Daily & 0.21 & 0.48 & 0.44 & 0.66 & 0.66 & 0.13 & 5.09 & $<0.01$ \\
\hline & Annual & 0.35 & 0.48 & 0.73 & 0.47 & -2.61 & 0.13 & -20.22 & $<0.01$ \\
\hline & ZINB & -0.02 & 0.49 & -0.04 & 0.96 & -0.01 & 0.13 & -0.08 & 0.94 \\
\hline & POIS & 0.33 & 0.48 & 0.69 & 0.49 & -0.10 & 0.13 & -0.79 & 0.43 \\
\hline & Daily:ZINB & 0.15 & 0.69 & 0.22 & 0.83 & -0.27 & 0.18 & -1.46 & 0.15 \\
\hline & Daily:POIS & -0.40 & 0.69 & -0.58 & 0.56 & -0.71 & 0.18 & -3.90 & $<0.01$ \\
\hline & Annual:POIS & -0.40 & 0.68 & -0.59 & 0.56 & -0.49 & 0.18 & -2.69 & 0.01 \\
\hline
\end{tabular}

For each species, we used the trends and credible intervals estimated for each simulated dataset $d$ to test whether bias (mean difference between estimated and simulated trends) and precision (mean of $0.5^{*}$ [upper credible interval-lower credible interval]) varied with count type (hourly, daily, or annual) and model structure (NB, ZINB, or POIS). We fit linear models that assumed a Gaussian data distribution (MASS function, Venables and Ripley 2002; R version 3.0.3, R Core Team 2014), and for each species, the difference between true and estimated trend or the half-width of the credible interval was the response variable $(\mathrm{n}=$ 100 datasets $\times 3$ count types $\times 2$ model structures $=600$ bias estimates), and data type (hourly, daily, annual), model structure (NB, ZINB, POIS) and their interaction were explanatory factors:

$$
\begin{gathered}
\text { bias }_{d} \sim \beta_{1} \times \text { data. }_{\text {type }}+\beta_{2} \times \text { structure }_{d}+\beta_{3} \\
\times \text { data.type }_{d} \times \text { structure }_{d}
\end{gathered}
$$

Model fit was assessed by examining plots of residuals.

To better understand how accuracy and precision of estimated trends influenced inference drawn, we also assessed for each species, data type, and model structure (1) proportion of simulated datasets where a trend was estimated with credible intervals $(\mathrm{CI})$ that included the simulated trend and did not include zero (hereafter "correct trend"); (2) proportion of simulated datasets with credible intervals that excluded the true trend (hereafter "error in CI"); (3) proportion of simulated datasets with estimated trend in the wrong direction (hereafter "error in direction"); and (4) proportion of simulated datasets with an error in direction and an error in CI (hereafter "error in CI/Dir").

\section{RESULTS}

Overall, trends tended to be negatively biased $(95 \%$ CI did not overlap the true trend) for the common species when trends were estimated using hourly counts, and when trends were estimated using daily totals and assuming a Poisson distribution of counts (Table 1, Fig.1, Fig. A4.1). Trends for the rare and over-dispersed species were unbiased, with $95 \%$ CI that included the true trend, for all data distributions and model structures (Fig. 1).

For the common and rare species, a similar distribution of trend estimates suggests that precision of the three model types was comparable among hourly, daily, and annual counts (Fig. 1). However, trends were less precise (larger CI) for both the common and rare species when annual totals were analyzed assuming a negative binomial distribution, suggesting poor model fit (Table 1, Fig. 2). In contrast, both the precision of the models (Fig. 1) and the precision of trends (Fig. 2) improved when counts of the overdispersed species were analyzed as annual totals as compared with hourly and daily counts.

For the common species, a Poisson data model resulted in comparable probabilities of detecting a correct trend, and comparable probabilities of error in CI, error in direction, and error in CI/Direction across all three data types (hourly, daily, 
Fig. 1. Box and whisker plots showing estimated trend $\%$ year ${ }^{-1}$ across 100 datasets simulated to represent a commonly detected species (e.g., Northern Harrier, Circus cyaneus), a rarely detected species with zero-inflated counts (e.g., Peregrine Falcon, Falco peregrinus) and a super-flocking species with highly over-dispersed (OD) counts (e.g., Broad-winged Hawk, Buteo platypterus). Results are shown for trends estimated using hourly, daily, and annual migration counts, and assuming a negative binomial (NB), zero-inflated NB (ZINB; hourly and daily data only), or Poisson (POIS) distribution of counts. Boxplots show 25th, 50th, 75th quartiles of the estimates, with black whiskers extending $1.5 *$ interquartile range in each direction. Mean $( \pm 95 \% \mathrm{CI})$ across simulated datasets are also shown by black dots with associated grey error bars. The solid horizontal line depicts the true, simulated trend of $-3.6 \%$ year- 1 .

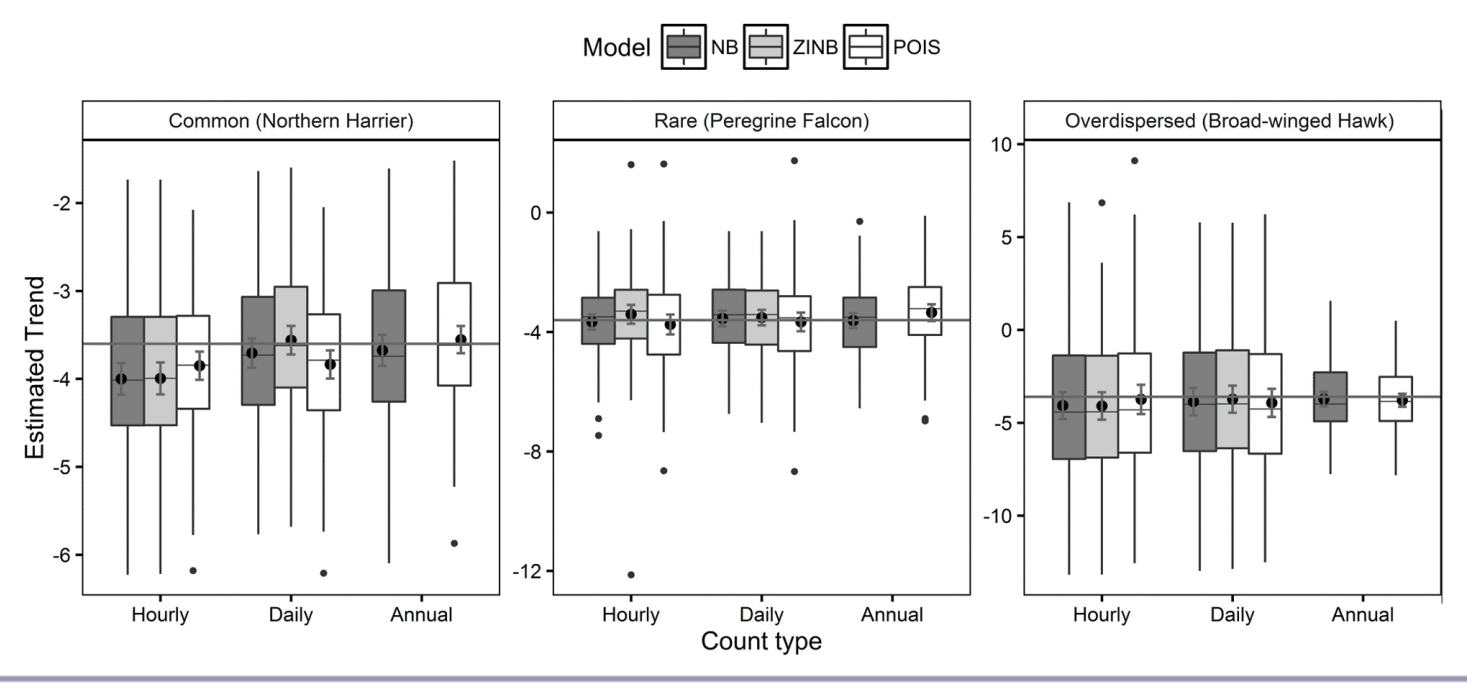

Fig. 2. Box and whisker plots showing the half-width of the credible interval $(0.5 \times$ (upper credible limit - lower credible limit)) of trend estimates across 100 datasets simulated to represent a commonly detected species (e.g., Northern Harrier, Circus cyaneus), a rarely detected species with zero-inflated counts (e.g., Peregrine Falcon, Falco peregrinus) and a super-flocking species with highly over-dispersed (OD) counts (e.g., Broad-winged Hawk Buteo platypterus). Results are shown for trends estimated using hourly, daily, and annual migration counts, and assuming a negative binomial (NB), zero-inflated NB (ZINB; hourly and daily data only), or Poisson (POIS) distribution of counts. Boxplots show 25th, 50th, 75th quartiles of the estimates, with black whiskers extending $1.5 *$ interquartile range in each direction.
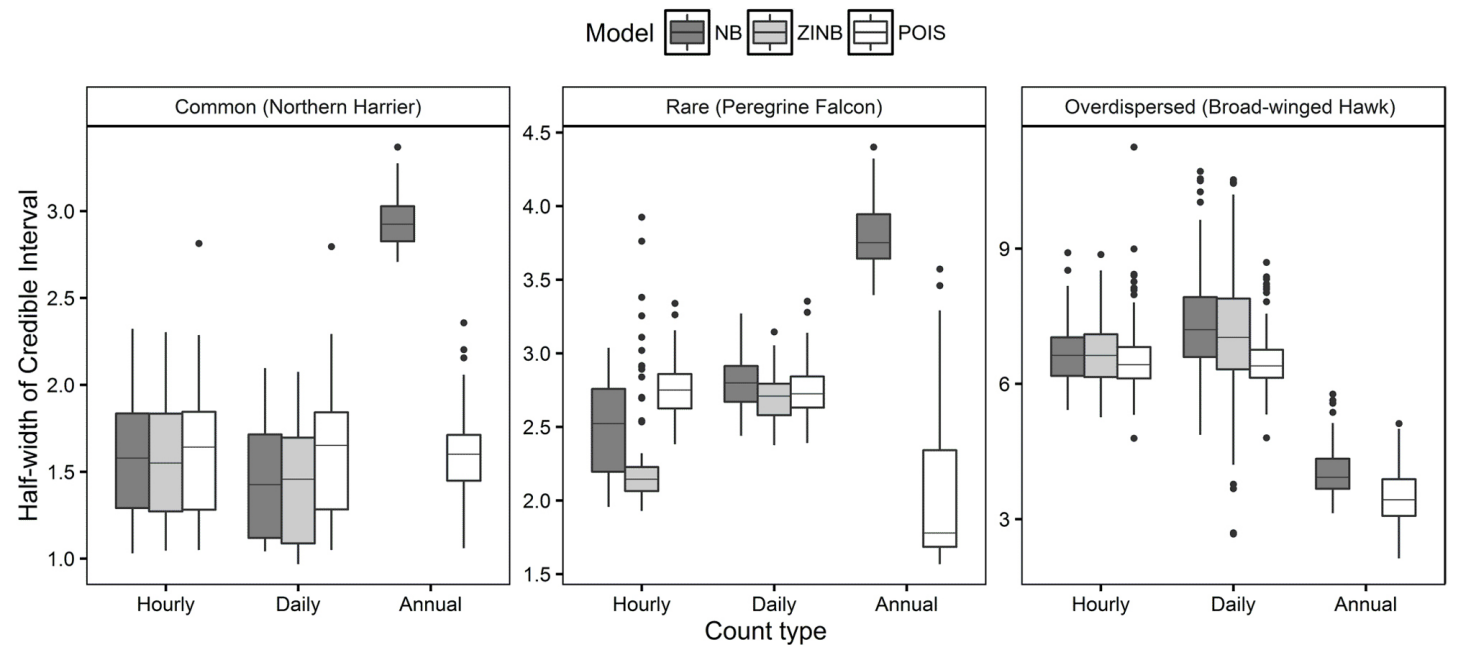

annual; Fig. 3). For the rare species, the probability of estimating a correct trend was greatest when hourly or daily counts were analyzed assuming an NB or ZINB data distribution, though the greater precision of hourly counts resulted in a slightly higher probability of estimating a trend with error in CI compared with daily and annual counts (Fig. 3). In contrast, estimating trends for the overdispersed species using annual counts and assuming a Poisson data distribution maximized the probability of 
Fig. 3. Proportion of 100 simulated datasets where (1) simulated trend fell within the $95 \%$ credible intervals (CI) of the estimated trend and CI did not include zero ("Correct"); (2) simulated trend fell outside the CI of the estimated trend (inaccurate; "Error CI"); (3) estimated trend was positive, i.e., in the wrong direction ("Error Dir"); and (4) estimated trend was in the wrong direction and credible intervals did not include the simulated trend ("Error CI/Dir"). Results are shown for data simulated to represent a commonly detected species (e.g., Northern Harrier, Circus cyaneus, NOHA), a rarely detected species with zero-inflated counts (e.g., Peregrine Falcon, Falco peregrinus, PEFA), and a super-flocking species with highly overdispersed counts (e.g., Broadwinged Hawk, Buteo platypterus, BWHA), analyzed as hourly, daily, or annual counts, and fit assuming either a negative binomial (NB) or zero-inflated NB (ZINB; hourly and daily data only), or Poisson (POIS) data model.
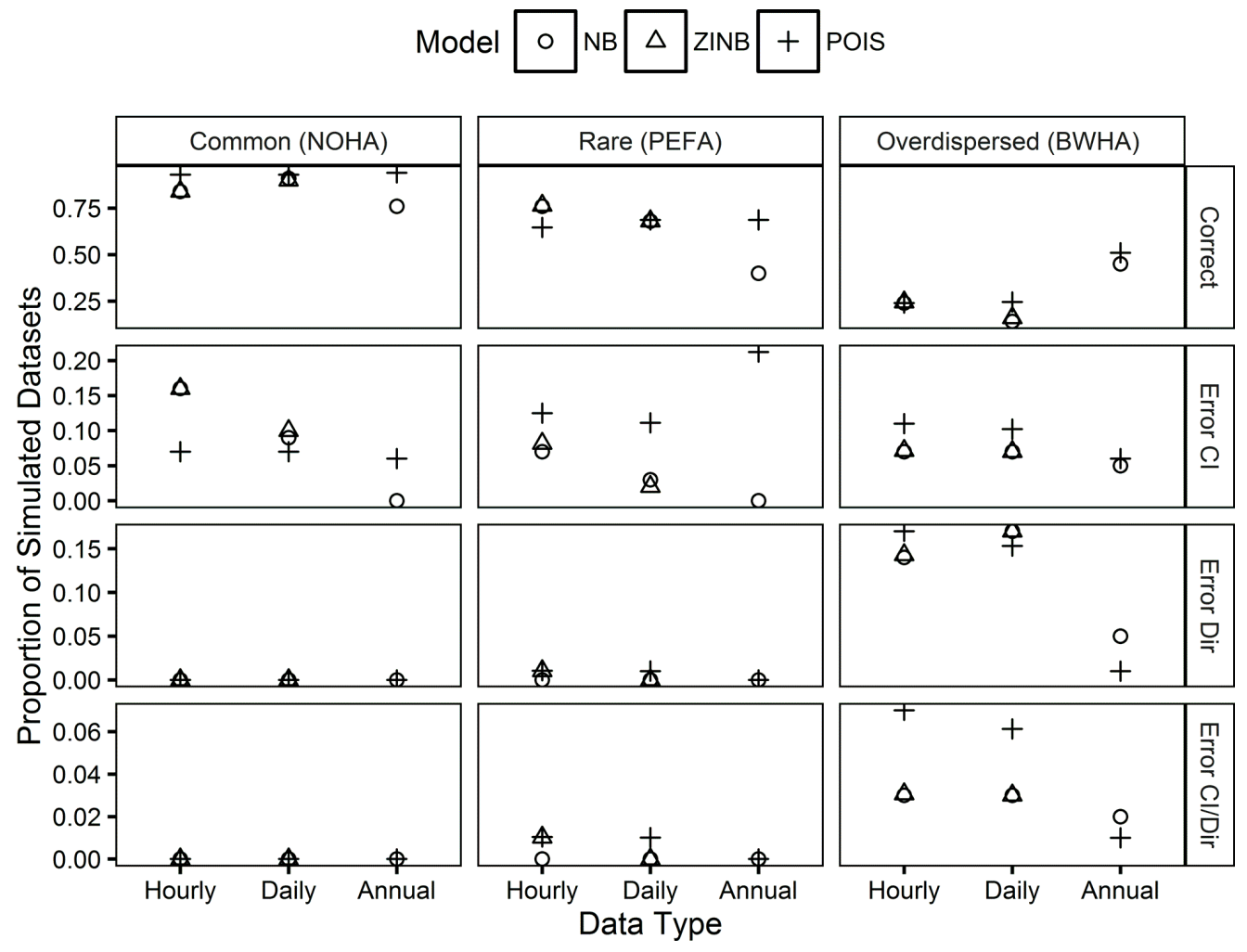

detecting a correct trend and minimized the probability of errors compared with the NB model and hourly and daily counts, though differences between data models were small. In no case was a significant error in direction detected for either species, i.e., an error in direction where the $\mathrm{CI}$ of the trend excluded both the true trend and zero.

\section{DISCUSSION}

Overall, our results suggest that there is no apparent reason to not aggregate hourly raptor migration count data into daily or annual totals for the analysis of long-term trends, provided a temporal trend in effort or other factor influencing detection probability has not occurred. For the overdispersed species in particular, a Poisson data model fit to annual counts minimized variability around mean bias and resulted in more precise trend estimates compared with hourly or daily counts or a negative binomial data distribution. This resulted in lower probabilities of estimating trends with CI that excluded the true trend and of estimating trends in the wrong direction. In general, these results support the work of Miller et al. (2002), who found that population trend was more precise when highly overdispersed raptor migration counts were analyzed as annual as opposed to daily totals. In contrast, trends of the rare species became less precise (larger CI) with aggregation from hourly to daily and annual totals. For this species, estimating trends using daily counts and assuming an NB data distribution appeared to balance maximizing the probability of detecting a correct trend (CI included true trend and excluded zero) and minimizing the probabilities of (1) estimating a trend with credible intervals that excluded the true trend or (2) estimating a trend in the wrong direction.

Hourly counts of the common species resulted in negatively biased trends. The same was not observed for the rare and overdispersed species, though with more simulations and an associated decline in variance, a difference in bias among data types might also become apparent for the overdispersed species. In general, we would not expect a difference in mean trend among 
data types given a good model fit and simulation model. Comparisons of simulated and real data suggest the overall distribution of hourly counts were comparable. However, compared to the rare and overdispersed species, counts of the common species were spread over a longer migration season (Appendix 2), and as a result, counts were more consistent over the season, with less of a migration peak. Further, the negative binomial dispersion parameters (k.day and k.hr, Appendix 2) were specified to more closely reflect a Poisson distribution of counts, and the negative binomial distribution tended to result in a more negative mean trend than the Poisson model for hourly data. Thus, a combination of simulation model specification and poor model fit might have led to the observed bias in trends for hourly (all models) and daily (Poisson model) counts of the common species.

Compared with an NB or Poisson data model, a ZINB data model applied to hourly or daily counts did not improve bias or precision of trends for any of the three species. Accounting for zeroinflation in addition to assuming overdispersed counts through an NB data distribution likely resulted in an overparameterized model. Further, in these simulations, additional zero observations were introduced to the data in response to simulated weather conditions. We did not subsequently include weather as a covariate to model zero-inflation independently. Doing so may have improved the performance of the ZINB model over the NB model, particularly for hourly migration counts.

The use of migration counts to estimate a population trend relies on the assumption that the relationship between migration counts and the population they are monitoring has not changed directionally over time. In other words, we assume that factors influencing the proportion of the monitored population detected each year varied randomly and not systematically over time (Crewe et al. 2015). In this study, we simulated random variation in sampling effort over time. Systematic variation in sampling effort, migration route (Vardanis et al. 2011), breeding and wintering distribution (Paprocki et al. 2014), or in stopover duration in response to climate change or other extrinsic factor, has the potential to bias population trends and lead to poor inference from results (Kéry and Schmidt 2008, Crewe et al. 2015). We did not assess whether or how aggregating counts in the presence of a systematic change in detection might affect the accuracy and precision of trends, though the simulations described here could be modified for that purpose. The analysis of real migration count data should take potential sources of detection bias into consideration, either by including ancillary data (e.g., weather, effort, habitat, stopover duration, methodology) as covariates, or, at a minimum, by explicitly stating how potential sources of bias might impact the results reported. Combining alternative sources of data from throughout the annual life cycle (Link et al. 2008, Paprocki et al. 2014), for example into an integrated population model (Link et al. 2008), also has the potential to improve inference drawn about population trends derived from migration counts.

The half-width of the credible interval was on average $4 \%$ /year for annual counts of the overdispersed species, and 3\%/year for daily counts of the rare species. It is not surprising, then, that the probability of estimating a trend in the correct direction with credible intervals that excluded 0 was less than 0.5 and 0.7 for the overdispersed and rare species, respectively, for the magnitude of change simulated here $\left(-3.6 \%\right.$ year $^{-1}$ over 20 years $)$. The rate of change we simulated was fairly extreme, and is a rate often used to assess population status of species at risk (COSEWIC 2012). Because rare species are typically those being assessed for conservation status, these results suggest that migration counts collected over a 20 -year period would detect this magnitude of decline only about $60 \%$ of the time for rare species with mean annual abundance less than 20 individuals per year (Table A2.2). Our ability to estimate a trend in the correct direction would improve with more extreme trends. More importantly, our ability to estimate an accurate trend would improve with length of the time series and with the number of sites providing monitoring data (Crewe et al. 2016b). Because the number of raptors and songbirds migrating and detected by counts can be largely influenced by weather (Hall et al. 1992, Allen et al. 1996, Barriocanal et al. 2002, Berthiaume et al. 2009) and other factors including observer differences (Sauer and Link 2002) or local habitat conditions (Harrison et al. 2000), modeling environmental or other relevant covariates to account for some of the observed variation in counts (Francis and Hussell 1998) might also improve precision, and therefore our ability to detect trends. The effect of including covariates for weather or other factors on model fit using hourly or daily count data should be explored, particularly for overdispersed species, which may then benefit from being analyzed as daily as opposed to annual totals (e.g., Crewe and McCracken 2015).

The analysis of Raptor Population Index (RPI) data as daily or annual totals has the potential to expand the geographic coverage of RPI trend results by including sites that are currently excluded because they submit daily and not hourly totals (Crewe et al. 2013). Although our results suggest that daily totals can be analyzed without consequence to the precision and accuracy of population trends when a systematic change in detection probability has not occurred, the submission of counts at the raw observation level would ensure that any change in effort, or other potentially biasing factor, can be identified and accounted for during the analysis and/or interpretation of trends. We thus recommend that count sites continue to submit data at the observation level, with as much detail as possible, including the number of hours and which hours were sampled each day, so that analysts can test for, and potentially account for, any systematic change in detection probability over time.

Responses to this article can be read online at: http://www.ace-eco.org/issues/responses.php/907

\section{Acknowledgments:}

We thank all of the staff and volunteers that collect raptor migration data annually at Hawk Mountain Sanctuary. This work was made possible by the facilities of the Shared Hierarchical Academic Research Computing Network (SHARCNET: www.sharcnet.ca) and Compute/Calcul Canada. John Brzustowski and Ge Baolai provided technical assistance with SHARCNET. Reviewer comments from Charles Francis greatly improved previous versions of this article. This report was prepared as part of the Raptor 
Population Index ( RPI) partnership of Bird Studies Canada, Hawk Mountain Sanctuary, the Hawk Migration Association of North America, and HawkWatch International (http://rpi-project.org/). This is Hawk Mountain Sanctuary contribution to conservation science number 264. Funding for this project was provided by an NSERC PGSB scholarship to T. L. C., a MITACS Accelerate Grant to T. L. C., P. D. T., Chris Guglielmo, and D. L. (Bird Studies Canada), and an NSERC Discover Grant to P. D. T.

\section{LITERATURE CITED}

Allen, P. E., L. J. Goodrich, and K. L. Bildstein. 1996. Withinand among-year effects of cold fronts on migrating raptors at Hawk Mountain, Pennsylvania, 1934-1991. Auk 113:329-338. http://dx.doi.org/10.2307/4088899

Barber, D. R., C. R. Fosdick, L. J. Goodrich, and S. Luke. 2001. Hawk Mountain Sanctuary migration count manual. Hawk Mountain Sanctuary Association, Kempton, Pennsylvania, USA. [online] URL: http://hawkcount.org/protocols/109/ hmsa_data_collection_protocol.pdf

Barriocanal, C., D. Montserrat, and D. Robson. 2002. Influences of wind flow on stopover decisions: the case of the Reed Warbler Acrocephalus scirpaceus in the Western Mediterranean. International Journal of Biometeorology 46:192-196. http://dx. doi.org/10.1007/s00484-002-0133-3

Berthiaume, É., M. Bélisle, and J.-P. Savard. 2009. Incorporating detectability into analyses of population trends based on hawk counts: a double-observer approach. Condor 111:43-58. http://dx. doi.org/10.1525/cond.2009.080081

Bildstein, K. L., J. P. Smith, E. Ruelas Inzunza, and R. R. Veit. 2008. State of North America's birds of prey. Nuttall Ornithological Club and American Ornithologists Union Series in Ornithology No.3. Cambridge, Massachusetts, and Washington, D.C., USA.

Bolker, B. 2008. Ecological models and data in R. Princeton University Press, Princeton, New Jersey, USA.

Crewe, T. L., and J. D. McCracken. 2015. Long-term trends in the number of monarch butterflies (Lepidoptera:Nymphalidae) counted on fall migration at Long Point, Ontario, Canada (1995-2014). Annals of the Entomological Society of America 108:707-717. http://dx.doi.org/10.1093/aesa/sav041

Crewe, T. L., J. D. McCracken, P. D. Taylor, D. Lepage, and A. E. Heagy. 2008. The Canadian migration monitoring network Réseau canadien de surveillance des migrations: ten-year report on monitoring landbird population change. Technical Report \#1. The Canadian Migration Monitoring Network - Réseau canadien de surveillance des migrations, Port Rowan, Ontario, Canada. [online] URL: http://www.bsc-eoc.org/download/CMMNReport2008. pdf

Crewe, T. L., P. D. Taylor, and D. Lepage. 2015. Modeling systematic change in stopover duration does not improve bias in trends estimated from migration counts. PLOS ONE 10:e0130137. http://dx.doi.org/10.1371/journal.pone.0130137

Crewe, T. L., P. D. Taylor, and D. Lepage. 2016a. Effect of sampling effort on bias and precision of trends in migration counts. Condor: Ornithological Applications 118:117-138.
Crewe, T. L., P. D. Taylor, D. Lepage, L. Goodrich, J. Brown, and J. Sodergren. 2013. The raptor population index, 2013 analysis methods and trend results. Raptor Population Index. [online] URL: http://rpi-project.org/2013/

Crewe, T. L., P. D. Taylor, D. Lepage, A. C. Smith, and C. M. Francis. 2016b. Quantifying regional variation in population trends using migration counts. Journal of Wildlife Management 80:245-255. http://dx.doi.org/10.1002/jwmg.1003

Committee on the Status of Endangered Wildlife in Canada (COSEWIC). 2012. COSEWIC assessment process, categories, and guidelines. COSEWIC, Gatineau Québec, Canada. [online] URL: http://www.cosewic.gc.ca/pdf/Assessment_process_and_criteria_e. pdf

Dail, D., and L. Madsen. 2011. Models for estimating abundance from repeated counts of an open metapopulation. Biometrics 67:577-587. http://dx.doi.org/10.1111/j.1541-0420.2010.01465.x

Dennis, E. B., S. N. Freeman, T. Brereton, and D. B. Roy. 2013. Indexing butterfly abundance whilst accounting for missing counts and variability in seasonal pattern. Methods in Ecology and Evolution 4:637-645. http://dx.doi.org/10.1111/2041-210X.12053

Dennis, E. B., B. J. T. Morgan, S. N. Freeman, D. B. Roy, and T. Brereton. 2016. Dynamic models for longitudinal butterfly data. Journal of Agricultural, Biological, and Environmental Statistics 21:1-21. http://dx.doi.org/10.1007/s13253-015-0216-3

Dunn, E. H. 2005. Counting migrants to monitor bird populations: state of the art. Pages 712-717 in C. J. Ralph and T. D. Rich, editors. Bird conservation implementation and integration in the Americas: Proceedings of the Third International Partners in Flight Conference, 2002 March 20-24, Asilomar, California. General Technical Report. PSW-GTR-191. U.S. Forest Service, Pacific Southwest Research Station, Albany, California, USA.

Farmer, C. J., D. J. T. Hussell, and D. Mizrahi. 2007. Detecting population trends in migratory birds of prey. Auk 124:1047-1062. http://dx.doi.org/10.1642/0004-8038(2007)124[1047:DPTIMB]2.0. $\mathrm{CO} ; 2$

Fedy, B. C., and C. L. Aldridge. 2011. The importance of withinyear repeated counts and the influence of scale on long-term monitoring of sage-grouse. Journal of Wildlife Management 75:1022-1033. http://dx.doi.org/10.1002/jwmg.155

Francis, C. M., and D. J. T. Hussell. 1998. Changes in numbers of land birds counted on migration at Long Point Bird Observatory, 1961-1997. Bird Populations 4:37-66.

Hall, L. S., A. M. Fish, and M. L. Morrison. 1992. The influence of weather on hawk movements in coastal northern California. Wilson Bulletin 104:447-461.

Harrison, N. M., M. J. Whitehouse, P. A. Prince, and N. Huin. 2000. What problems do local habitat change represent for the constant effort site ringing scheme? Ringing \& Migration 20:1-8. http://dx.doi.org/10.1080/03078698.2000.9674220

Hochachka, W. M., and W. Fiedler. 2008. Trends in trappability and stop-over duration can confound interpretations of population trajectories from long-term migration ringing studies. Journal of Ornithology 149:375-391. http://dx.doi.org/10.1007/ s10336-008-0282-1 
Kéry, M., R. M. Dorazio, L. Soldaat, A. van Strien, A. Zuiderwijk, and J. A. Royle. 2009. Trend estimation in populations with imperfect detection. Journal of Applied Ecology 46:1163-1172. http://dx.doi.org/10.1111/j.1365-2664.2009.01724. $\mathrm{x}$

Kéry, M., and A. J. Royle. 2010. Hierarchical modelling and estimation of abundance and population trends in metapopulation designs. Journal of Animal Ecology 79:453-461. http://dx.doi.org/10.1111/j.1365-2656.2009.01632.x

Kéry, M., and B. R. Schmidt. 2008. Imperfect detection and its consequences for monitoring for conservation. Community Ecology 9:207-216. http://dx.doi.org/10.1556/ComEc.9.2008.2.10

Knudsen, E., A. Lindén, T. Ergon, N. Jonzén, J. O. Vik, J. Knape, J. E. Røer, and N. Stenseth. 2007. Characterizing bird migration phenology using data from standardized monitoring at bird observatories. Climate Research 35:59-77. http://dx.doi. org/10.3354/cr00714

Link, W. A., and J. R. Sauer. 2002. A hierarchical analysis of population change with application to Cerulean Warblers. Ecology 83:2832-2840. http://dx.doi.org/10.1890/0012-9658(2002) 083[2832:AHAOPC]2.0.CO;2

Link, W. A., J. R. Sauer, and D. K. Niven. 2008. Combining breeding bird survey and Christmas bird count data to evaluate seasonal components of population change in Northern Bobwhite. Journal of Wildlife Management 72:44-51. http://dx. doi.org/10.2193/2007-299

Miller, M. W., E. M. Greenstone, W. Greenstone, and K. L. Bildstein. 2002. Timing and magnitude of broad-winged hawk migration at Montclair Hawk Lookout, New Jersey, and Hawk Mountain Sanctuary, Pennsylvania. Wilson Bulletin 114:479-484. http://dx.doi.org/10.1676/0043-5643(2002)114[0479:TAMOBW]2.0. $\mathrm{CO} ; 2$

Nichols, J. D., L. Thomas, and P. B. Conn. 2009. Inferences about landbird abundance from count data: recent advances and future directions. Pages 201-235 in D. L. Thomson, E. G. Cooch, and M. J. Conroy, editors. Modeling demographic processes in marked populations. Springer, New York, New York, USA. http://dx.doi. org/10.1007/978-0-387-78151-8_9

Paprocki, N., J. A. Heath, and S. J. Novak. 2014. Regional distribution shifts help explain local changes in wintering raptor abundance: implications for interpreting population trends. $P L o S$ ONE 9:e86814. http://dx.doi.org/10.1371/journal.pone.0086814

R Core Team. 2014. R: a language and environment for statistical computing. R Foundation for Statistical Computing, Vienna, Austria. [online] URL: http://www.r-project.org

Ross, B. E., M. B. Hooten, and D. N. Koons. 2012. An accessible method for implementing hierarchical models with spatiotemporal abundance data. PLoS ONE 7:e49395. http://dx.doi. org/10.1371/journal.pone.0049395
Royle, J. A., R. B. Chandler, K. D. Gazenski, and T. A. Graves. 2013. Spatial capture-recapture models for jointly estimating population density and landscape connectivity. Ecology 94:287-294. http://dx.doi.org/10.1890/12-0413.1

Rue, H., S. Martino, and N. Chopin. 2009. Approximate Bayesian inference for latent Gaussian models using integrated nested Laplace approximations. Journal of the Royal Statistical Society B 71:319-392. http://dx.doi.org/10.1111/j.1467-9868.2008.00700. $\mathrm{x}$

Sauer, J. R., and W. A. Link. 2002. Hierarchical modeling of population stability and species group attributes from survey data. Ecology 83:1743-1751. http://dx.doi.org/10.1890/0012-9658 (2002)083[1743:HMOPSA]2.0.CO;2

Vardanis, Y., R. H. G. Klaassen, R. Strandberg, and T. Alerstam. 2011. Individuality in bird migration: routes and timing. Biology Letters 7:502-505. http://dx.doi.org/10.1098/rsbl.2010.1180

Venables, W. N., and B. D. Ripley. 2002. Modern applied statistics with $S$. Fourth Edition, Springer, New York, New York, USA. http://dx.doi.org/10.1007/978-0-387-21706-2

Zipkin, E. F., B. Gardner, A. T. Gilbert, A. F. O’Connell Jr, J. A. Royle, and E. D. Silverman. 2010. Distribution patterns of wintering sea ducks in relation to the North Atlantic Oscillation and local environmental characteristics. Oecologia 163:893-902. http://dx.doi.org/10.1007/s00442-010-1622-4
Editor-in-Chief: Keith A.Hobson Subject Editor: Charles M.Francis
Sponsored by the Society of Canadian Ornithologists and Bird Studies Canada Parrainée par la Société des ornithologistes du Canada et Études d'oiseaux Canada

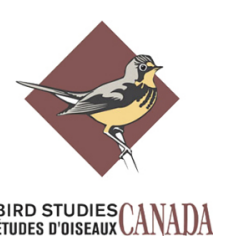


Appendix 1. Summary of real migration count data.

Table A1.1. Mean, median, range and coefficient of variation (CV) for annual, daily and hourly counts, proportion of 0-observation days and hours ('0-Obs Days', '0-Obs Hours'), and number of days between first and last detection ('N Days') for three raptor species detected at Hawk

Mountain Sanctuary, Pennsylvania (1991-2010). Values were used as a guide to simulate data with a similar distribution of counts.

\begin{tabular}{|c|c|c|c|c|c|}
\hline Variable & Species & $\overline{\text { Mean }}$ & Median & Range & $\mathrm{CVV}$ \\
\hline \multirow[t]{3}{*}{ Annual Count } & Northern harrier & 210 & 194 & $(118-338)$ & 0.31 \\
\hline & Peregrine falcon & 46 & 45 & $(24-67)$ & 0.26 \\
\hline & Broad-winged hawk & 6800 & 6381 & $(1773-11838)$ & 0.42 \\
\hline \multirow[t]{3}{*}{ Daily Count } & Northern harrier & 2 & 1 & $(0-36)$ & 1.34 \\
\hline & Peregrine falcon & 1 & 0 & $(0-30)$ & 2.35 \\
\hline & Broad-winged hawk & 120 & 9 & $(0-7508)$ & 3.44 \\
\hline \multirow[t]{3}{*}{ Hourly Count } & Northern harrier & 0 & 0 & $(0-13)$ & 2.31 \\
\hline & Peregrine falcon & 0 & 0 & $(0-9)$ & 5.02 \\
\hline & Broad-winged hawk & 19 & 0 & $(0-4927)$ & 5.47 \\
\hline \multirow[t]{3}{*}{ 0-Obs Days } & Northern harrier & 0.33 & 0.32 & $(0.22-0.49)$ & 0.21 \\
\hline & Peregrine falcon & 0.69 & 0.68 & $(0.62-0.85)$ & 0.07 \\
\hline & Broad-winged hawk & 0.20 & 0.19 & $(0.12-0.28)$ & 0.25 \\
\hline \multirow[t]{3}{*}{ 0-Obs Hours $†$} & Northern harrier & 0.82 & 0.82 & $(0.74-0.88)$ & 0.05 \\
\hline & Peregrine falcon & 0.94 & 0.94 & $(0.92-0.97)$ & 0.01 \\
\hline & Broad-winged hawk & 0.57 & 0.56 & $(0.51-0.66)$ & 0.08 \\
\hline \multirow[t]{3}{*}{ N Days $\ddagger$} & Northern harrier & 95 & 97 & $(78-102)$ & 0.07 \\
\hline & Peregrine falcon & 40 & 39 & $(15-65)$ & 0.29 \\
\hline & Broad-winged hawk & 53 & 54 & $(42-58)$ & 0.08 \\
\hline
\end{tabular}


† Across years, median first and last date of detection for Northern Harrier: Aug. 22, Nov. 27; for Peregrine Falcon: Sept. 13, October 22; for Broad-winged Hawk: Aug. 14 , Oct. 8. ‡ Data collected between 06:30 and 17:15 were included in calculations. 
Appendix 2. Simulation parameter values and simulation data summary.

Table A2.1. Parameter values used to simulate hourly raptor migration counts for a common (e.g., Northern Harrier), rare (e.g., Peregrine Falcon), and a super-flocking species (e.g., Broadwinged Hawk). For simulation code, see 'Crewe et al. (2016) Effect of sampling effort on bias and precision of trends in migration counts. The Condor: Ornithological Applications 118:117138 .

\begin{tabular}{lccc}
\hline Simulation Parameter & Common & Rare & Super-flocking \\
\hline nyears & 20 & 20 & 20 \\
Y.1 & 500 & 50 & 12500 \\
trend & -0.036 & -0.036 & -0.036 \\
trend.err & 0.2 & 0.1 & 0.4 \\
sday & -60 & -37 & -30 \\
sday.err & 9 & 3 & 3 \\
prob.move & 0.95 & 0.95 & 0.90 \\
weath.pois & 1.2 & 1.2 & 1.2 \\
m.peak & 32 & 10 & 8 \\
m.peak.err & 5 & 2 & 2 \\
m.spread & 0 & 0 & 2 \\
m.spread.err & 0.8 & 0.8 & 0.8 \\
day.err & 0.05 & 0.1 & 0.1 \\
k.day & 13 & 6 & 0.07 \\
shr & -9 & -9 & -5 \\
shr.err & 1 & 1 & 0.5 \\
m.peak.hr & 3 & 3 & 2 \\
m.peak.err.hr & 0.3 & 0.3 & -2 \\
m.spread.hr & -2 & -2 & \\
\hline
\end{tabular}




\begin{tabular}{lccc}
\hline m.spread.err.hr & 0.4 & 0.4 & 0.4 \\
hr.err & 0.1 & 0.1 & 0.3 \\
k.hr & 5 & 1 & 0.6 \\
\hline
\end{tabular}

Table A2.2. Mean across 100 simulated datasets of the mean, median, standard deviation (SD) and coefficient of variation (CV) for annual, daily and hourly counts, proportion of 0-observation days and hours, and number of days between first and last detection for three raptor species.

\begin{tabular}{|c|c|c|c|c|c|}
\hline Variable & SpeciesCode & Mean & Median & $\overline{S D}$ & $\mathrm{C \textrm {CV }}$ \\
\hline \multirow[t]{3}{*}{ Annual Count } & Northern Harrier & 192.5 & 185.18 & 59.39 & 0.31 \\
\hline & Peregrine Falcon & 19.31 & 18.84 & 7.59 & 0.39 \\
\hline & Broad-winged Hawk & 6870.26 & 6150.87 & 3639.39 & 0.53 \\
\hline \multirow[t]{3}{*}{ Daily Count } & Northern Harrier & 2.3 & 1 & 3.21 & 1.39 \\
\hline & Peregrine Falcon & 0.55 & 0 & 1.22 & 2.25 \\
\hline & Broad-winged Hawk & 175.6 & 9.28 & 557.14 & 3.16 \\
\hline \multirow[t]{3}{*}{ Hourly Count } & Northern Harrier & 0.24 & 0 & 0.65 & 2.73 \\
\hline & Peregrine Falcon & 0.06 & 0 & 0.31 & 5.38 \\
\hline & Broad-winged Hawk & 21.98 & 0 & 119.43 & 5.42 \\
\hline \multirow[t]{3}{*}{0 Obs. Days } & Northern Harrier & 0.43 & 0.43 & 0.09 & 0.20 \\
\hline & Peregrine Falcon & 0.76 & 0.76 & 0.07 & 0.10 \\
\hline & Broad-winged Hawk & 0.33 & 0.31 & 0.12 & 0.37 \\
\hline \multirow[t]{2}{*}{0 Obs. Hours } & Northern Harrier & 0.84 & 0.85 & 0.04 & 0.05 \\
\hline & Peregrine Falcon & 0.96 & 0.96 & 0.02 & 0.02 \\
\hline
\end{tabular}




\begin{tabular}{llcccc}
\hline & Broad-winged Hawk & 0.60 & 0.60 & 0.09 & 0.16 \\
N Days Detect & Northern Harrier & 97.37 & 98.99 & 5.94 & 0.06 \\
& Peregrine Falcon & 29.50 & 30.18 & 7.51 & 0.26 \\
& Broad-winged Hawk & 42.16 & 43.66 & 5.67 & 0.14 \\
\hline
\end{tabular}


Appendix 3. Comparisons of real and simulated raptor migration counts.

Table A3.1. Mean, min and max of Pearson correlation of qq-scores between real and simulated migration count datasets $(\mathrm{n}=100)$ for a common (Northern Harrier), rare (Peregrine Falcon) and overdispersed (Broad-winged Hawk) raptor species. A Pearson correlation near 1 suggests a comparable distribution of counts between datasets. In all cases, $p<0.0001$. Real data were collected at Hawk Mountain Sanctuary, Pennsylvania (1991-2010).

\begin{tabular}{lccc}
\hline \hline \multicolumn{1}{c}{ Species } & Mean & Min & Max \\
\hline Broad-winged Hawk & 0.96 & 0.90 & 1.00 \\
Northern Harrier & 0.93 & 0.91 & 0.96 \\
Peregrine Falcon & 0.93 & 0.88 & 0.96 \\
\hline
\end{tabular}

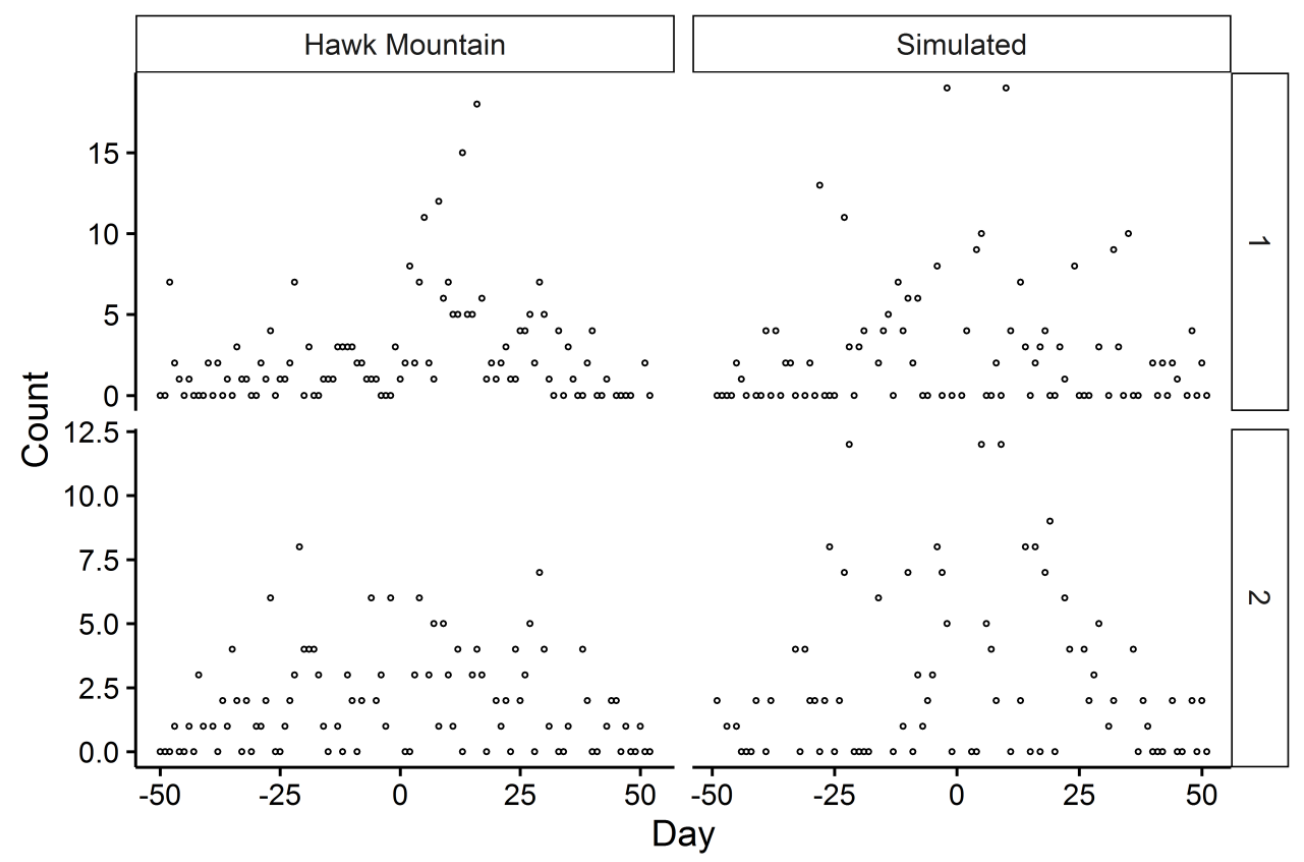

Figure A3.1. Example distribution of real and simulated daily migration counts for a commonly detected species (Northern Harrier). Real migration counts were collected at Hawk Mountain Sanctuary, Pennsylvania in 2000 (year 1, top panel) and 2001 (year 2, bottom panel). 


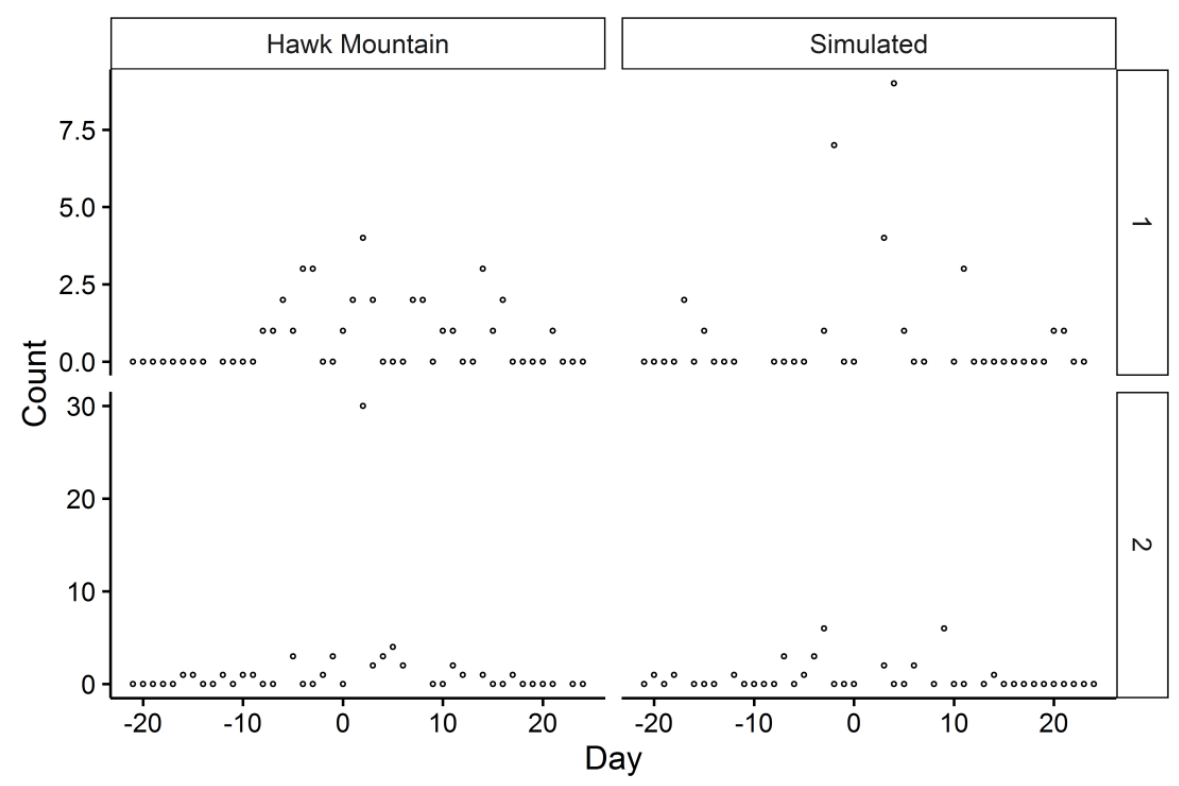

Figure A3.2. Example distribution of real and simulated daily migration counts for a rarely detected species (Peregrine Falcom). Real migration counts were collected at Hawk Mountain Sanctuary, Pennsylvania in 2000 (year 1, top panel) and 2001 (year 2, bottom panel).

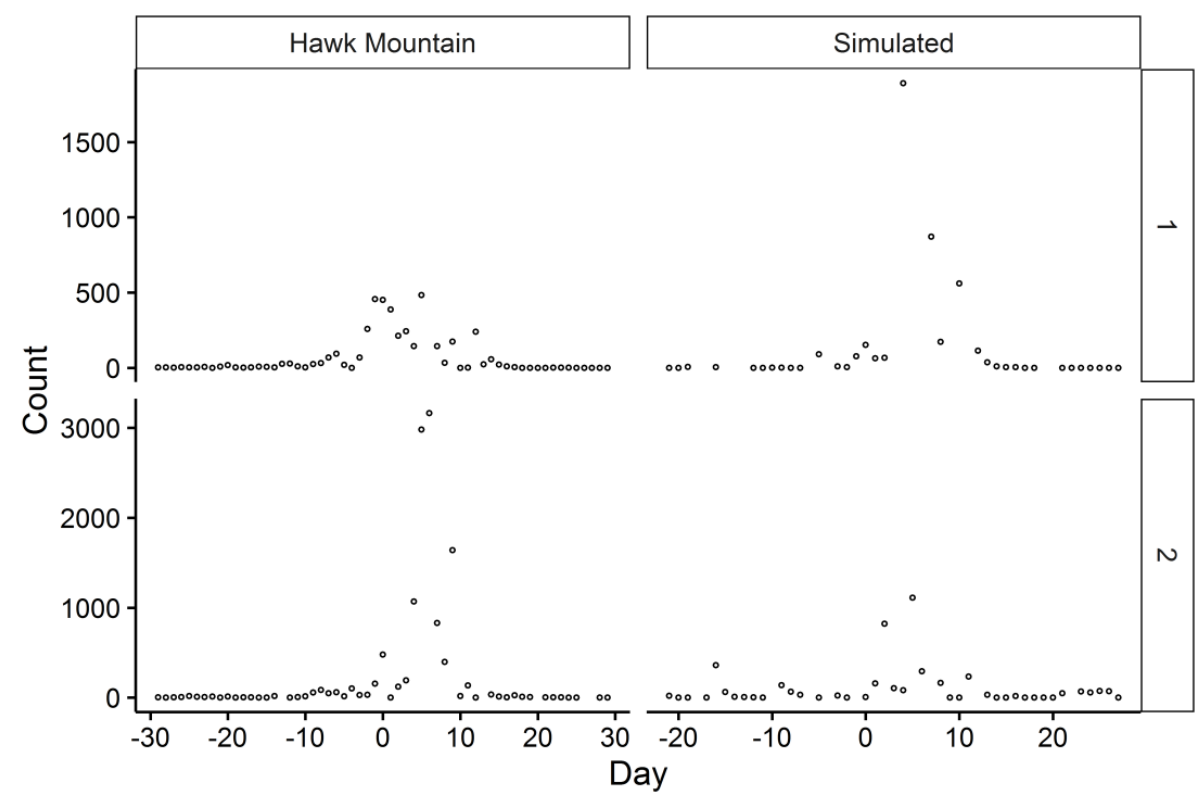

Figure A3.3. Example distribution of real and simulated daily migration counts for a species with highly overdispersed counts (Broad-winged Hawk). Real migration counts were collected at Hawk Mountain Sanctuary, Pennsylvania in 2000 (year 1, top panel) and 2001 (year 2, bottom panel). 


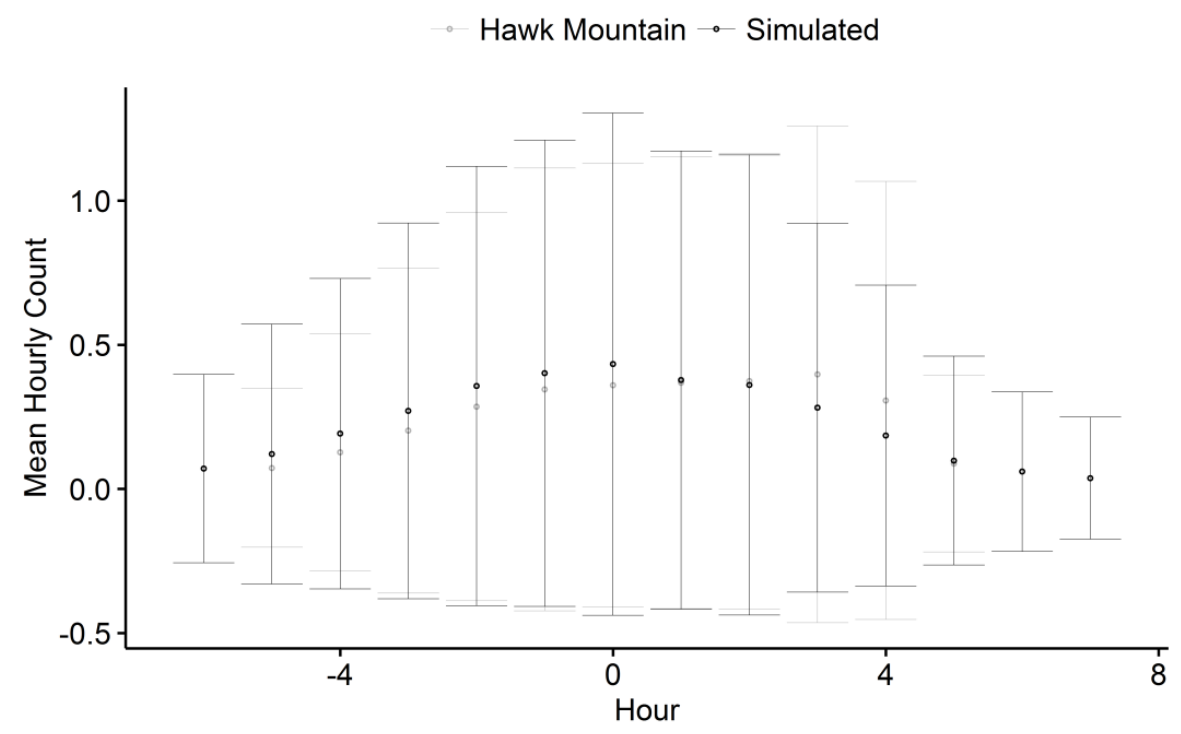

Figure A3.4. Comparison of mean (SD) raptor migration count by hour of the day between data collected at Hawk Mountain, Pennsylvania (1966-2010) and simulated data (20 years), for a commonly detected species (Northern Harrier).

Hawk Mountain - Simulated

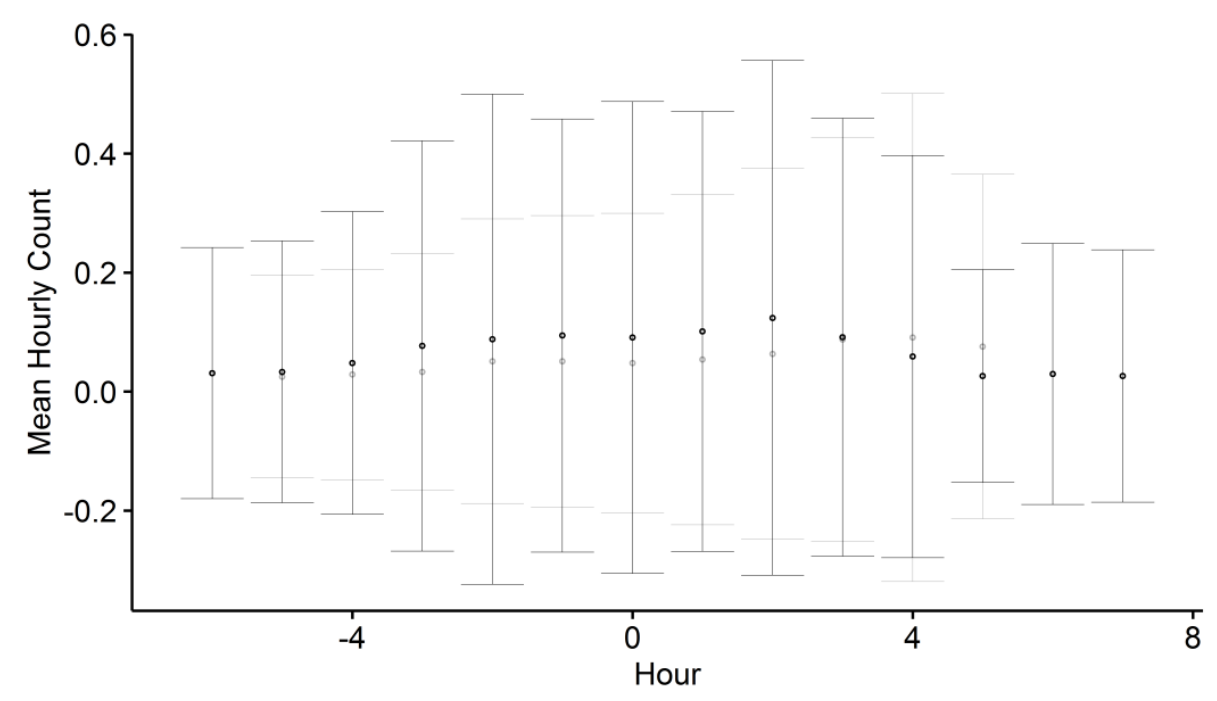

Figure A3.5. Comparison of mean (SD) raptor migration count by hour of the day between data collected at Hawk Mountain, Pennsylvania (1966-2010) and simulated data (20 years), for a rarely detected species (Peregrine Falcon). 


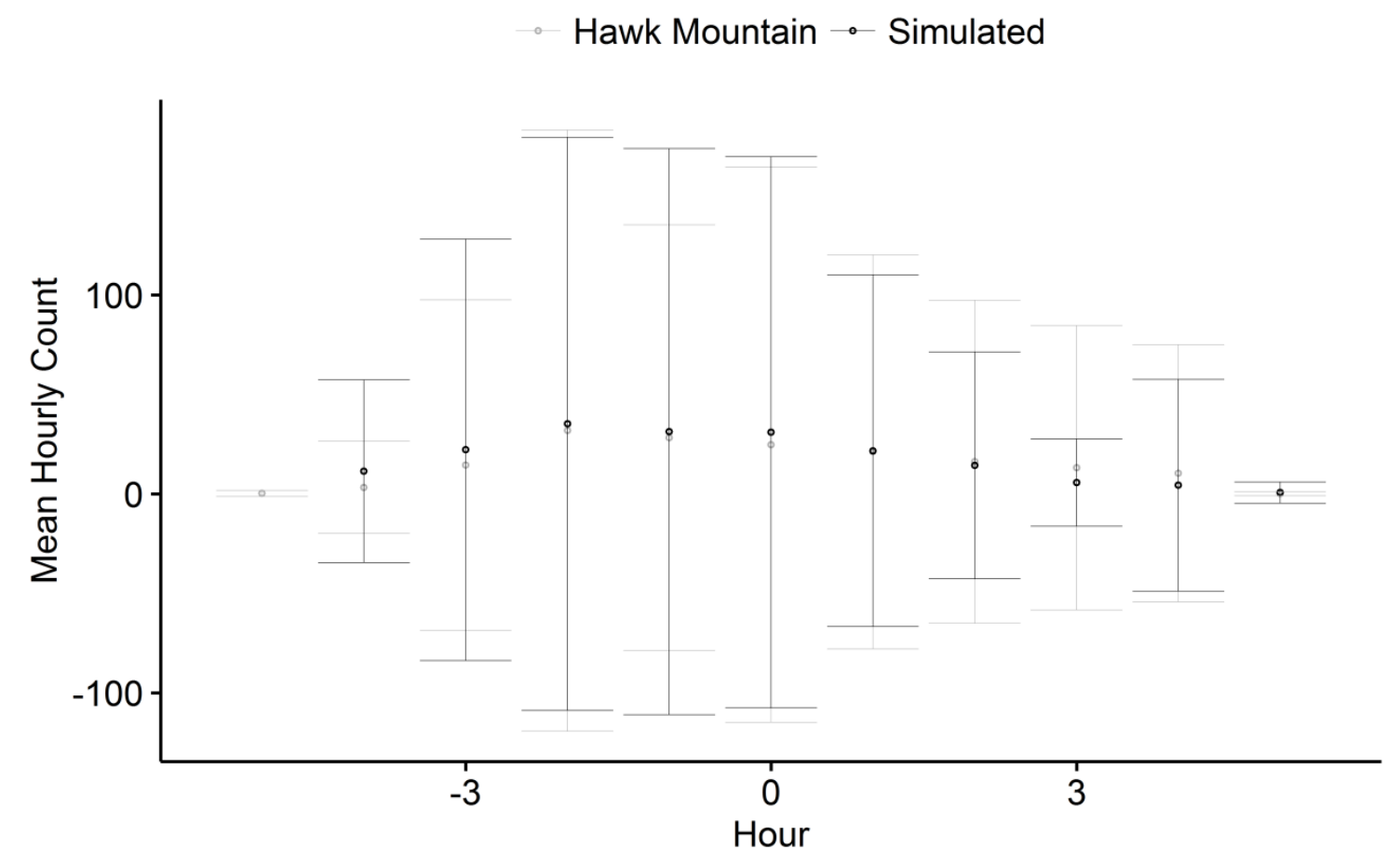

Figure A3.6. Comparison of mean (SD) raptor migration count by hour of the day between data collected at Hawk Mountain, Pennsylvania (1966-2010) and simulated data (20 years), for a species that typically has highly overdispersed counts (Broad-winged Hawk). 
Appendix 4. Additional comparisons of estimated trend among species and data distributions.

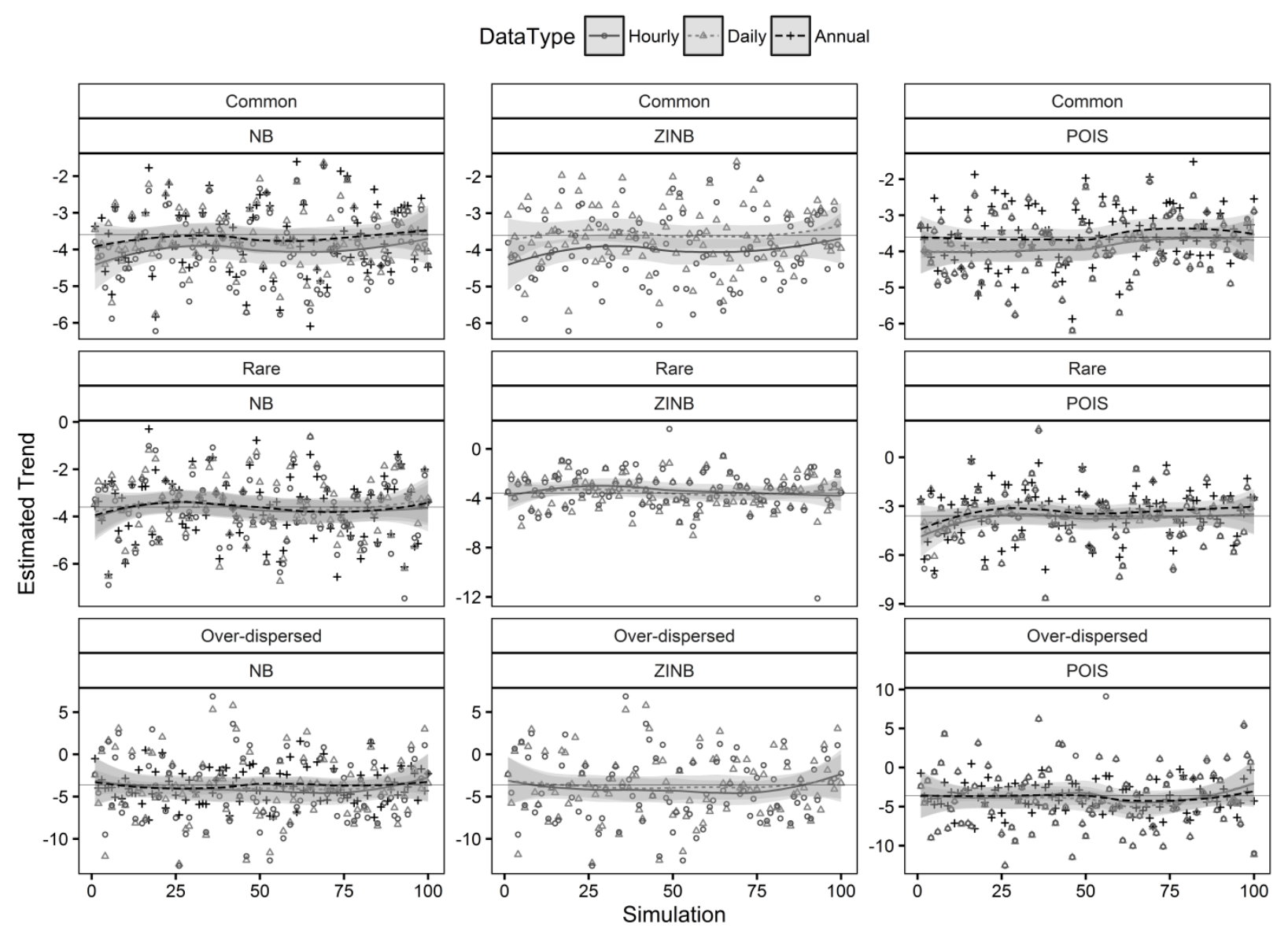

Figure A4.1. Scatter plots with loess smooth, showing estimated trend (\%year $\left.{ }^{-1}\right)$ for each of 100 datasets simulated to represent a commonly detected species (e.g., Northern Harrier), a rarely detected species with zero-inflated counts (e.g., Peregrine Falcon) and a super-flocking species with highly overdispersed counts (e.g., Broad-winged Hawk). Results are shown for trends estimated using hourly, daily and annual migration counts, and assuming a negative binomial (NB), zero-inflated NB (ZINB; hourly and daily data only), or Poisson (POIS) distribution of counts. The solid grey horizontal line depicts the true, simulated trend of $-3.6 \%$ year $^{-1}$. 